\title{
FEDERALISMO NO BRASIL E NO MUNDO: UM DELINEAMENTO HISTÓRICO E CRÍTICO SOBRE A SEPARAÇÃO DE PODERES
}

\author{
Caroline Limberger Costa ${ }^{1}$
}

\begin{abstract}
RESUMO: O presente estudo procura discorrer sobre a história do federalismo, desde o seu surgimento remoto na Idade Média até o marco fundamental de sua composição: a Constituição norte-americana. Neste ínterim, também discorrer-se-á, sobre o espaço brasileiro, afinal, é imperioso conhecer a história para aprofundar um conhecimento mais concreto do nosso país. Procurar-se-á analisar, em ultima instância, a separação dos poderes, prevista por Montesquieu, na obra denominada 'Espírito das Leis', a qual adveio como uma solução aos problemas encontrados na Constituição norte-americana, possibilitando criar um sistema de freios e contrapesos, reprimindo qualquer tipo de abuso por parte dos poderes.
\end{abstract}

PALAVRAS-CHAVE: Federalismo, Separação de Poderes, República, Teoria de Montesquieu.

\section{Federalism in Brazil and the world: design a historical and critical about the separation of powers}

ABSTRACT : This study seeks to discuss the history of federalism, since its emergence in the remote Middle Ages to the cornerstone of its composition: the U.S. Constitution. Meanwhile, also will talk about the Brazilian space, after all, it is imperative to know the history to deepen a more concrete understanding of our country. Will be analyzed, ultimately, the separation of powers laid down by Montesquieu, in the work titled 'Spirit of Laws', which sprang as a solution to problems encountered in the U.S. Constitution, enabling it to create a system of checks and balances, suppressing any kind of abuse by the powers.

KEYWORDS: Federalism, Separation of Powers, Republic, Theory of Montesquieu.

\section{INTRODUÇÃ̃}

O presente ensaio procurará verificar a relação existente entre o federalismo e suas vertentes no mundo e no Brasil. Num primeiro momento, perquirir-se-á sobre a

\footnotetext{
${ }^{1}$ Acadêmica do Curso de Direito da UNISC. Bolsista PIBIC/CNPq, sob orientação do Prof. Dr. Rogério Gesta Leal. Integrante do Grupo de Estudos e Pesquisas "Estado, Administração Pública e Sociedade", vinculado ao CNPq. Endereço eletrônico: carolinecosta89@gmail.com.
} 
história do federalismo, transcorrendo sobre a Constituição Americana de 1787 e a sua conjuntura que serviu de base para a implementação do federalismo no Brasil.

Num segundo momento discorrer-se-á sobre a separação dos poderes, inspirado na obra de Montesquieu "Do Espírito das Leis", servindo de apoio para a construção da interdependência dos poderes: executivo, legislativo e judiciário. Também observar-se-á os diversos fundamentos desenvolvidos por outros autores, como Aristóteles e Locke, sendo que para este, deveria haver uma hierarquia entre os poderes, sendo o poder legislativo o absoluto, questionando-se a sua aplicação nos dias atuais.

Assim, procurar-se-á realizar um estudo interpretativo sobre teoria da separação de poderes, a fim de buscar artifícios axiológicos de como esta teoria aplica-se atualmente e o que mudou deste o seu surgimento, questionando sua aplicação nos dias atuais.

Em último momento, observar-se-á o sistema de freios e contrapesos, explanado na obra de Montesquieu. É um sistema que tenta refrear os abusos que possam ocorrer por um dos poderes em relação aos demais, lembrando que se trata de um controle recíproco, que procura sempre garantir a efetividade da Constituição e a proteção das garantias legais.

\subsection{FEDERALISMO: uma visão histórica e crítica}

O Estado Federal, teoricamente, apareceu com a Constituição dos Estados Unidos de 1787. Antes disso pouco se falava em federalismo, apenas ocorriam algumas manifestações embrionárias durante a Idade Média, na Suíça e na Itália (BARROSO, 1982, p. 07). A Constituição Americana adveio como uma substituição dos "Articles of Confederation", os quais surgiram por "necessidade de união das treze ex-colônias que se libertaram da dominação inglesa, mas que, ainda fracamente estruturadas como Estados independentes, tinham um adversário em comum” (BARROSO, 1982, p. 08). Barroso quer dizer que essa independência representava o perigo de retorno à subjugação colonial, e que se reunindo todos os Estados, preservaria a soberania e permitiria e emancipação da metrópole (BARROSO, 1982, p. 09). Ferreri destaca: 
Hoje, pode-se dizer que a federação norte-americana é muito diferente do modelo idealizado pelos seus criadores. As antigas idéias federalistas baseadas nas concepções autonomistas de caráter territorial do séc. XVIII, são agora, apenas reminiscências históricas. A edificação constitucional que criou o federalismo norte-americano, transformou-se no que na atualidade os autores denominam de 'um novo federalismo'. Parece que o Estado moderno americano conseguiu equilibrar o poder absorvente do Estado com as imprescritiveis necessidades da liberdade humana. Novas incumbências foram designadas ao Estado Federal, redefinindo irreversivelmente sua função (FERRERI, 1995, p. 20).

O Brasil ter escolhido o sistema federalista para configurar seu sistema de estado, mesmo por influência norte-americana, não constitui uma cópia deste, como ensina Souza, uma vez que "sua adoção foi precedida de debates e porque as elites regionais eram favoráveis à descentralização, vista como sendo alcançável por um sistema federal e não por um sistema unitário" (SOUZA, 2005, p. 107).

Notoriamente o processo de federalização do território brasileiro foi mais lento e demorado que outros países, pois, além de enfrentar problemas de extensão territorial e de diferenças culturais e regionais dos povos, o Brasil era um Estado Unitário e descentralizado, o que acabou colaborando retardar esse processo (FERRERI, 1995, p.27).

O federalismo foi inserido no Brasil em 1889 com a proclamação da República, o qual, segundo Mendes e Gall, constituiu "uma frágil e dinâmica forma de cooperação política para divisão de poder e responsabilidade entre União, estados e municípios. Cada uma das esferas de governo tem os seus próprios órgãos governamentais" (MENDES; GALL p. 02). Neste ínterim, Dallari explica:

O Estado Federal indica, antes de tudo, uma forma de Estado, não de governo. Entretanto, há um relacionamento muito estreito entre a adoção da organização federativa e os problemas de governo, pois quando se compõe 
uma federação isto quer dizer que tal forma de convivência foi considerada mais conveniente para que, sob um governo comum, dois ou mais povos persigam objetivos comuns. Ultimamente têm surgido muitos Estados com organização federativa, o que deve significar que esse tipo de Estado é visto como capaz de corresponder às necessidades e aspirações fundamentais de nossa época (DALLARI, 2005, p. 255).

O conceito de federalismo no Brasil condicionou-se por dois fatores essenciais: o desnivelamento no desenvolvimento regional que leva à centralização do governo e a dimensão do território brasileiro, impondo "a necessidade da descentralização do comando, pelo estabelecimento de governos locais”, como ensina Barroso (1982, p. 03).

Inicialmente, a autonomia dos Estados, conquistada em 1891, não se ampliava aos municípios (FERRERI, 1995, p. 28). O federalismo não era respeitado na prática, pois, como ensina Ferreri (1995), "os juízes e tribunais locais ficaram subordinados aos tiranos que monopolizavam o poder em cada unidade federal”. Mouskheli destaca:

Il s'organise suivant le type de l'État federal, c'est-à-dire suivant le type où il y a des collectivités-membres qui sont des États 'au sens du droit national', ce qui veut dire qu'ils sont subordonnés directement au droit national, au droit de l'État, 'au sens du droit internacional'; c'est celui-ci qui leur confere la compétence et l'autonomie constitutionnelle; il leur est superordonné, Il est d'um degré plus haut dans la hiérarchie dês ordres juridiques (FERRERI, 1995, p. 28) ${ }^{2}$.

A ideia de ingressar em uma federação é a última decisão soberana de um Estado, uma vez que a partir desse momento, sua soberania pertence à União, e agora fica obrigado a obedecer às ordens do governo central (DALLARI, 1986, p. 17). A participação dos Estados na soberania federal remete a conclusão de que os membros da

\footnotetext{
2 Tradução Livre: "É organizado de acordo com o tipo de Estado federal, do tipo onde existem comunidades que são Estados 'na acepção do direito nacional', que quer dizer, que eles estão diretamente subordinados à legislação nacional, ao direito do Estado 'na acepção do direito internacional'; e é isto que lhes confere a competência e a autonomia constitucional; que é um dos degraus mais altos da hierarquia das ordens jurídicas".
} 
federação não são soberanos, uma vez que "não possuem o caráter de Estado na sua definição conceitual e definitiva" (BARACHO, 1986, p. 28).

Quanto à soberania do Estado Federal, adentra-se em uma grande incógnita. Para muitos autores, como Le Fur, admite-se a repartição da soberania, em afirmações como:

[...] touts ce auteurs partent de ce fait que, dans l'État federal, l'État central et les États particuliers participent, d'une manière déterminée par la constitucion fédérale, à l'exercice du pouvoir public; de même que l'État fédéral, les États particuliers possèdent en propre un certain nombre d'attributions qui leur sont confiées par la constitution; dans les limites de ces attribuions, ils sont indépendants, dit-on, de tout autre pouvoir, donc souvains, de même que l'État fédéral l'est dans sa sphère (LE FUR, 1896, p. 480)³.

Já outros autores, como Mouskheli (1931, p. 73), negam que a soberania seja essencial ao Estado Federal, afirmando que, «existe-t-il une différence essentielle entre l'État d'une parte et la commune, la province autonome et l'État-membre d'un État fédéral d'autre part? $»^{4}$. Mouskheli, (1931, apud BARACHO, 1986, p. 21) ensina que, apenas o Estado central é considerado soberano e que os Estados-membros não diferem, por exemplo, das comunas nem das províncias, a não ser pela participação na formação da vontade popular.

Sobre o pacto federativo, Bobbio explica que, o equilíbrio constitucional é essencial para manter a prioridade da Constituição, afirmando:

[...] a autonomia desse modelo se traduz no fato de que o poder de decidir concretamente, em caso de conflito, quais sejam os limites que as duas ordens de poderes soberanos não podem ultrapassar, não pertence nem ao poder

\footnotetext{
${ }^{3}$ Tradução Livre: “[...] todos os autores partem do fato de que, no Estado federal, o Estado central e os Estados individuais participam de uma forma determinada pela Constituição Federal: o exercício do poder público; de igual forma que o Estado federal, os Estados individuais possuem uma série de funções específicas que lhes são atribuídas pela Constituição; e dentro dos limites de suas atribuições, eles são independentes de qualquer outro poder, assim como o governo federal está dentro de sua esfera".

${ }^{4}$ Tradução Livre: "Existe diferença entre o estado de uma parte da cidade, da província autônoma e o Estado-membro de um Estado federal por outro?".
} 
central (como acontece no Estado unitário, onde as coletividades territoriais menores usufruem de uma autonomia delegada) nem aos Estados federado como acontece no sistema confederativo, que não limita a soberania absoluta dos Estados (BOBBIO, 1989, p. 481).

No próximo tópico far-se-á uma analise detalhada da relação do federalismo com a separação de poderes e como estes interagem de modo a não conflitarem entre si.

\section{TEORIA DA SEPARAÇÃO DOS PODERES: uma análise das funções típicas e atípicas dos poderes do Estado}

Dentre os diversos problemas enfrentados durante o período da elaboração da Constituição norte-americana, Dallari (1986, p. 30) ensina que, a partir da obra Do Espírito das Leis, de Montesquieu, parte destes foram resolvidos. A solução encontrada foi a separação de poderes, distribuindo as diversas funções sem sobreposição de nenhuma. Destarte, Dallari explica:

[...] não bastava dar ao povo a possibilidade de escolher os governantes, se estes acumulassem tamanho poder que pudessem desprezar depois a vontade do povo. E Montesquieu oferecia solução para esse problema propondo uma distribuição do poder entre vários ramos, de tal modo que nenhum pudesse agir com tirania. Por outro lado, era preciso não enfraquecer demais o poder dos governantes, para não reduzir a eficiência do governo e para não estimular a ambição de algum indivíduo ou grupo de indivíduos, que, não vendo a possibilidade de grande resistência, ficassem tentados a tomar o poder pela força (DALLARI, 1986, p. 30).

A teoria da separação dos poderes começou a ser desenvolvida por volta do século XVII, com o objetivo de proteger a liberdade individual e enfraquecer o poder da Coroa dominante até então (GONÇALES, 2006, p. 05). Neste sentido, Montesquieu observa: 
Quando, na mesma pessoa ou no mesmo corpo de Magistratura, o Poder Legislativo é reunido ao Executivo, não há liberdade. Porque pode temer-se que o mesmo Monarca ou mesmo o Senado faça leis tirânicas para executá-las tiranicamente. Também não haverá liberdade se o Poder de Julgar não estiver separado do Legislativo e do Executivo. Se estivesse junto com o Legislativo, o poder sobre a vida e a liberdade dos cidadãos seria arbitrário: pois o Juiz seria o Legislador. Se estivesse junto com o Executivo, o Juiz poderia ter a força de um opressor. Estaria tudo perdido se um mesmo homem, ou um mesmo corpo de principais ou nobres, ou do Povo, exercesse estes três poderes: o de fazer as leis; o de executar as resoluções públicas; e o de julgar os crimes ou as demandas dos particulares. (MONTESQUIEU, 1996, p. 75)

Importante ressaltar que não foi apenas Montesquieu que tratou deste tema pertinente à separação de poderes. Muito antes dele, encontra-se Aristóteles, incontestavelmente uma das fontes de origem, o qual "construiu sua teoria política a partir do exame de inúmeras constituições concretas" (CARVALHO, 2008, p. 166). Essa teoria foi abordada pela Constituição Mista, a qual está focada no "sentido de separação como meio de limitação do poder, preocupando-se com os modos de exercício do poder supremo" (BITTENCOURT, 2008, p. 43). Assim, dita o autor:

A Constituição é uma ordem ou a distribuição de poderes que existem num Estado, isto é, a maneira que eles são divididos, a desde a soberania e o fim que se propõe a sociedade civil. As leis não são a mesma coisa que os artigos fundamentais da Constituição; elas servem apenas de regra para os magistrados no exercício do governo, e também para conter os refratários (ARISTÓTELES, 1991, p. 131).

Locke, delimitado por Delacampgne (2001, p. 18) fundador do liberalismo político, criou o preceito da separação de poderes e assim, distingue-se de Aristóteles no sentido deste, estabelecer três espécies de poder: legislativo, executivo e federativo. $\mathrm{Na}$ teoria de Locke, existe uma hierarquia entre os poderes, sendo o legislativo, o poder superior a todos os outros. Assim Carvalho ensina: 
O Poder Federativo se refere ao direito de fazer a paz e a guerra, de celebrar tratados e alianças e de conduzir os negócios com pessoas e comunidades estrangeiras, e corresponde a uma faculdade de cada homem no estado natural, antes, pois, de entrar em sociedade. Relativamente ao Poder Legislativo, a comunidade delega à maioria parlamentar o exercício do poder de fazer as leis. Assim, há uma supremacia do Poder Legislativo dentro do Estado. Há necessidade, contudo, de uma exigência de separação de Poderes (orgânico-pessoal) entre o Poder Legislativo e Poder Executivo: para que a lei seja imparcialmente aplicada é necessário que não a apliquem os mesmos homens que a fazem, pois não há nenhum titular do Poder que dele não possa abusar (CARVALHO, 2008, p. 178).

A teoria de separação de poderes de Locke fundamenta-se no ideal da distinção do Poder Legislativo e do Poder Executivo. Grohmann é enfático ao afirmar que a relação entre esses poderes caracteriza a oposição entre a eficiência governativa e a representação política, ou seja, a garantia de mobilidade do governo e o respeito à representação da sociedade na polis (GHOHMANN, 2001, p. 117). Para ele, “o Estado de natureza é um estado de perfeita harmonia, sendo que a Constituição e a atuação do Estado se justificam apenas para a defesa dos direitos naturais, sendo que neles se inclui a ideia marcante de propriedade privada" (GHOHMANN, 2001, p. 117).

Destarte observa-se:

No âmbito da relação Executivo-Legislativo a eficiência diz respeito à crença de que um governo só terá governabilidade caso o seu programa seja aprovado na íntegra ou pelo menos nos aspectos principais, assim como as decisões devem ser tecnicamente bem feitas e implementadas com a rapidez que os problemas atuais, complexos e extensos, exigem. Essa necessidade envolve a complexidade de governar através das leis, as quais tenderiam crescentemente a mesclar atos administrativos com atos normativos gerais. Dessa forma, a relação entre o Poder Executivo e o Poder Legislativo se modifica. Do Legislativo não cabe mais a emanação monopolizada da legislação. E, assim, reforça-se o Executivo pela capacidade de legislar e 
administrar o Estado e suas políticas. Mas o caminho não é de mão única. $O$ Legislativo tem sua compensação quando pode alocar certos recursos de forma particularizada, tomando parte no processo de execução, incluindo a interface direta com agências da burocracia pública (GHOHMANN, 2001, p. 118).

Grohmann (2001, p. 120) afirma que existem alguns instrumentos institucionais, os quais proporcionam o poder de uma estrutura diante de outra. O primeiro (rule making), é o jeito como se vai emitir a legislação, que obedece a certas leis determinadas pelo Legislativo; o segundo (delegated decree authority) constitui o poder autorizado pelo Legislativo para que o Executivo estabeleça leis; o terceiro (constitucional decree authority), corresponde às normas constitucionais que estabelecem o poder de cada um (GHOHMANN, 2001, p. 120). O autor também ensina que há ainda a questão da representação política, ou seja, “o executivo e o legislativo são dois âmbitos de representação política igualmente legítimos (tratando-se de um regime democrático, portanto, com sua fundação também democraticamente estabelecida), porque seus ocupantes são escolhidos em eleições livres e democráticas" (GHOHMANN, 2001, p. 120).

Montesquieu inspirou-se parcialmente na ideia de John Locke para formular sua teoria fundamentada na representação e na separação de poderes, a qual assegura a viabilidade do governo e cria um ambiente propício para que nenhum dos poderes sobressaia a outro (VIEIRA, 1997, p. 43). Em 1748, Montesquieu lançou o livro 'O Espírito das Leis', fazendo "uma análise minuciosa da estrutura bicameral do Parlamento britânico" (ALBUQUERQUE, 1995, p. 119). Como ensina Bonavides:

Montesquieu foi, incontestavelmente, um clássico do liberalismo burguês. O que há de mais alto na sua doutrina da separação dos poderes, segundo o consenso dos melhores tratadistas, é que nele a divisão não tem apenas caráter teórico, como em Locke, mas corresponde a uma distribuição efetiva e prática do poder entre titulares que não se confundem (BONAVIDES, 1993, p. 49). 
Em 'Espírito das Leis', Montesquieu procurou buscar uma relação harmoniosa entre os poderes, a qual refrearia os abusos e possíveis excessos que possam vir a ocorrer. Essa teoria chamou-se: teoria dos freios e contrapesos, ou checks and balances. Desse modo, o Tribunal Regional Federal da $4^{\mathrm{a}}$ Região faz uma belíssima explanação:

Dar efetividade ao sistema de freios e contrapesos que deve permear a atuação dos três poderes da união, o qual se justifica não somente pela necessidade de frear os abusos que eventualmente possam ser cometidos por um dos poderes em face dos demais, senão também evitar excessos no tratamento dos direitos e das garantias fundamentais dos cidadãos (BRASIL, 2006, p. 03).

Complementando Streck e Bolzan, discorrem:

Atualmente, seria preferível falarmos em colaboração de poderes, particularmente no âmbito do parlamentarismo e de independência orgânica e harmonia dos poderes, quando do presidencialismo, embora mesmo isso sofra os influxos da organização sociopolítico-econômica atual, podendo-se melhor falar em exercício preponderante de certas atribuições por determinados órgãos do poder público estatal ou, como é o caso das funções executiva e jurisdicional no campo da aplicação do direito no caso concreto, onde o que diferencia é a maior ou menos eficácia conclusiva do ato praticado ou da decisão (STRECK E BOLZAN, 2001, p. 165).

Montesquieu foi apto do uso arbitrário do poder "até o momento em que este encontre limites e, para que não se permita que se instaure a tirania faz-se necessário que as coisas se organizem de modo que o poder limite o próprio poder" (PIEROBON, 2006, p. 03). Neste ínterim, o autor também ensina que especificamente a partir de 1789, "a definição de direitos fundamentais, começam a surgir nas constituições dos Estados, a constituição tem neste primeiro momento, o intuito de limitar o poder do Estado e garantir a liberdade política e social dos indivíduos" (PIEROBON, 2006, p. 03). Ao contrário de John Locke, é possível perceber que: 
[...] para Montesquieu, há três poderes: o Poder Legislativo, que é o de fazer leis, por um certo tempo ou para sempre, de corrigir ou ab-rogar as existentes; o Poder Executivo das coisas que dependem do direito das gentes, isto é, de fazer a paz ou a guerra, de enviar ou receber as embaixadas, de manter a segurança e de prevenir as invasões; o poder de julgar ou o Poder Executivo das coisas que dependem do Direito Civil, que se traduz no poder de punir os crimes ou de julgar os litígios entre os particulares (CARVALHO, 2008, p. 167).

Para concluir, em relação à separação dos poderes, é possível perceber que com o passar do tempo, a ideia inicial dessa teoria tornou-se adaptável a nova realidade da sociedade. Neste sentido, o Ministro Eros Grau explana, nos dizeres de Souza (2006), que o ideal "seria traçar uma separação entre as funções do Estado, de acordo com um critério material”, o que geraria a seguinte classificação: “a) função normativa - de produção das normas jurídicas (= textos normativos); b) função administrativa - de execução das normas jurídicas; c) função jurisdicional - de aplicação das normas jurídicas", explica a autora.

\section{CONSIDERAÇÕES FINAIS}

Diante das delimitações supracitadas, percebe-se que o federalismo, mais do que apenas garantir a soberania do estado, visa estabelecer um equilíbrio constitucional, protegendo assim as garantias previstas em lei, as quais se mostram essenciais a uma vida digna e honesta. Inicialmente observa-se que este equilíbrio não era respeitado, sendo a autonomia dos Estados e Municípios quase mínima, para não dizer nula. Entretanto, com o advento da Constituição Federal de 1988, veio a consagrar no seu $\operatorname{artigo} 2^{\circ}$, a teoria da separação dos poderes, conferindo independência e harmonia entre os poderes Executivo, Legislativo e Judiciário. 
Observa-se que a ideia inicial da Teoria da Separação de Poderes era de proteger o individuo frente aos abusos que poderiam advir e enfraquecer o poder da Coroa. Esta teoria passou por diversas mudanças ao longo do tempo, como vislumbra o Ministro Eros Grau - que para sua acepção, deve-se utilizar um critério material, ou seja, uma separação das funções - típicas e atípicas.

O sistema de freios e contrapesos ou checks and balances, com a obra de Montesquieu, adveio para estabelecer um controle recíproco, impondo limites aos possíveis abusos praticados por um dos poderes em relação aos demais. Com este sistema, nenhum poder possuirá total independência nem será hierarquicamente superior aos demais, a fim de manter um sistema equilibrado que se regula por si mesmo.

\section{REFERÊNCIAS BIBLIOGRÁFICAS}

ALBUQUERQUE, J. A. Guilhon. Montesquieu: sociedade e poder In: WEFFORT, Francisco (Org). Os Clássicos da Política. São Paulo: Ática, 1995.

ARISTÓTELES. A Política. Tradução de Roberto Leal Ferreira. São Paulo: Martins Fonte, 1991.

BARACHO, José Alfredo de Oliveira. Teoria Geral do Federalismo. Rio de Janeiro: Forense, 1986.

BARROSO, Luis Roberto. Direito Constitucional Brasileiro: o problema da federação. Rio de Janeiro: Ed. Forense, 1982.

BITtencourt, Caroline M. Repensando a Teoria da Separação de Poderes: Novas Perspectivas com Relação ao Judiciário em face da Necessidade de Realização da Dignidade da Pessoa Humana no Estado Democrático de Direito. 2008. 197 f. Dissertação (Programa de Pós-Graduação em Direito - Mestrado) - Universidade de Santa Cruz do Sul, Santa Cruz do Sul, 2008. 
BOBBIO, Norberto; MATTEUCCI, Nicola; PASQUINO, Gianfranco. Dicionário de Política. Brasília: Editora Universidade de Brasília, 1989.

BONAVIDES, Paulo. Do Estado Liberal ao Estado Social. Livraria Del Rey Editora. Belo Horizonte. 1993.

BRASIL, Tribunal Regional Federal da $4^{\text {a }}$ Região. Embargos Infringentes em Apelação Cível 2004.70.00.006893-3 - $2^{\text {a }}$ S. Rel. Juiz Fed. Fernando Quadros da Silva - DJU 08.11.2006.

CARVALHO, Kildare Gonçalves. Direito Constitucional. 14 ed. Belo Horizonte: Del Rey, 2008.

DELACAMPGNE, Christian. A filosofia política hoje: idéias, debates, questões. Trad. Lucy Magalhães. Rio de Janeiro: Jorge Zahar Ed., 2001.

DALlARI, Dalmo de Abreu. Elementos de Teoria Geral do Estado. São Paulo: Saraiva, 2005.

O Estado Federal. São Paulo: Ed. Ática, 1986.

GONÇALES, Juliana Callado. Separação de Poderes. In.: II Encontro de Iniciação científica e I Encontro de Extensão Universitária.v.2. 2006.

GROHMANN, Luis Gustavo Mello. O Poder Legislativo no Rio Grande do Sul: 1995 a 1998. In.; SANTOS, Fabiano. O Poder Legislativo nos Estados: diversidade e convergência. Rio de Janeiro: Editora FGV, 2001.

FERRERI, Janice Helena. A Federação. In.: BASTOS, Celso (org.). Por uma Nova Constituição. São Paulo; Editora dos Tribunais, 1995. 
LE FUR, Louis. État Fédéral et Confederátion D’États. Paris: Ed. Pantheon-Assas, 1896.

MENDES, Marcos J.; GALL, Norman. O que é federalismo?. In.: Braudel Papers.

MONTESQUIEU. O Espírito das Leis. São Paulo: Martins Fontes, 1996.

MOUSKHELI, Michel. La Théorie Juridique de l'État Fédéral. Paris: A. Pedone Editeur, 1931.

PIEROBON, Flávio. (Re) Leitura da Separação de Poderes; uma Análise em busca da efetividade constitucional. v. 2. 2006.

SOUZA, Celina. Federalismo, Desenho Constitucional e Instituições Federativas no Brasil Pós-1988. In.: Rev. Sociologia Política, Curitiba, nº 24, p. 105-121, jun. 2005.

SOUZA, Lara Gomides de. A separação dos poderes e as funções precípuas de cada um deles - publicado em 09/08/2006. Disponível em: <www.lfg.com.br>. Acesso em 05 de Outubro de 2011.

STRECK, Lenio Luiz; BOLZAN DE MORAIS, José Luis. Ciência Política e Teoria Geral do Estado. $2^{\text {a }}$ Ed. Porto Alegre; Livraria do Advogado, 2001.

VIEIRA, Luiz Vicente. A Democracia em Rosseau: a recusa dos pressupostos liberais. Porto Alegre: EDIPUCRS, 1997. 